\title{
The Role of Managers in Crafting and Implementing a Quality Assurance Strategy within the Public Universities of the Republic of Kosovo
}

\author{
Shqiponja Nallbani
}

shqiponja.nallbani@unhz.eu

\author{
Doi:10.5901/ajis.2015.v4n2s1p187
}

\begin{abstract}
Public universities in our country, much like European universities, are seeking to create effective academic mechanisms in order to establish a "Kosovo of Knowledge" society. In this regard, they must take more responsibility to ensure quality, and in return, also demand from the government and civil society to assume their share of responsibility in order to enable universities to provide resources that will allow them to meet the mission in the best possible manner. This would allow academic institutions to be competitive not only in the area of higher education system but also in a broader spectrum. It is not only Europe, but the entire world is becoming a "knowledge society", and Kosovo, as a country in transition, has no alternative but to join this effort. To achieve this, MEST together with all stakeholders of higher education, have an obligation to continuously review and harmonize the legislative framework and strategic documents pertaining to quality assurance, and thus become active and creative participants in line with the terms and standards arising from the Treaty of Lisbon. The lack of a clear quality assurance strategy pushes the university away from the European Zone of Higher Education and Research. Among the most important stakeholders to design and implement this strategy are the managers of all university levels. For this delicate task to take root, lawmaking institutions and universities must change the mentality and the concept of university management. The chief stakeholder of this concept should be the Rector, assuming major managerial roles and responsibilities, unlike until now being mainly an academic Rector. Therefore, the mission of the "Kosovo of Knowledge" and the role of the public universities are warranted only through the transformation and harmonization of the domestic legal framework with the international one and the enhancing managerial competences for the university leadership.
\end{abstract}

Keywords: university, management quality, Rector, knowledge

\section{Introduction}

Education is considered an important factor of sustainable development of human resources, economic welfare, for the preservation of peace and security, development of universal values and improvement of quality of life at the individual, family, social and global level. The Republic of Kosovo recognizes and encourages this right and its significance to the country. The education system in place, since the time the declaration of independence, has undergone intensive changes. New legislation and programs on education have been issued and are being reviewed since then. Rapid developments of global dimensions in the field of education, science and technology are directly associated with the teaching process, in particular with the aim of improving and increasing the quality in this very important process. As such, the achievement of these goals in educational institutions is closely related to the professional management of such institutions.

The aspect of management in education institutions within Kosovo is in a very serious condition. Educational institutions are being managed by professors who are not prepared in theoretical and practical terms on managing an educational institution. They do not know the concepts and principles of management. If the success of a business organization depends on its manager, then why is the success of a university not dependent on the management skills of rector of an educational institution? How is it possible for the management of a business organization or a company, which is involved in the provision of goods or services, engage well prepared experts in theory and in practice, whereas for the management of a university institution, which has to do with building mental, emotional and psycho-physical human capacities, engage professors who are not prepared with skills to manage the institution. In this regard the main proof for the consequences is the poor results and, consequently, the level of education and the practical skills of people who complete education in educational institutions in Kosovo is relatively very low, with an exception of individual cases.

Expectations are high with regards to the overall university performance and the professional qualification of professors and managers specifically. Despite the number of higher education providers in the country, it is important to focus in the process of transforming a university education from a quantitative to a qualitative education. The overall state 
of education of the population of a country partly determines the level of education of the workforce in that country (including people working as employees or self-employed, entrepreneurs, managers, officials and many other professions). Different countries place an emphasis on different components of education.

The purpose of the modern university in the country should be accompanied with the redefining of the role of the university Rector. A Rector with managerial competences should include the category of academic staff who are visionaries, educational planners, promoters of university development, communicators and engagers to ensure broad community participation, supporting quality in teaching and learning, intermediating the main stakeholders at the university, managing technical and financial resources, leading their staff and students and make informed decisions based on data gathered, and who are effectively strategic in a growing competitive context in order to achieve the best results possible for their students with the resources available (Manual for the Establishing of a Framework for Quality in Higher Education, Graz, Prishtinë, Salzburg, 2011, taken from web:

http://www.wus-austria.org/files/docs/Quality\%20Assurance\%20Manual_FINAL\%20ENGLISH.pdf).

The European Organization on Quality (EOQC) has adopted a general definition of quality: "Quality is the degree to which the product meets needs of users - consumers", and with respect to the quality of the learning process, it is the ability of a university, of professors, administration and services staff - to meet the needs of students.( European Organization for Quality (EOQC) - http://www.eoq.org/about_eoq/eoq_charter_mission_vision.html)

\section{The Role of the Rectorate in Ensuring and Managing Quality}

The term ensuring and managing quality, or the system framework for ensuring and managing quality, usually refers to a formal management system that is used to strengthen a bearer of Higher Education.( Marioara A \& Cristina - Petrina D., " The Management and content of managerial functions in Romania Universities" http://www.utgjiu.ro/revista/ec/pdf/201306/37_Avram,\%20Dragusin.pdf) It is through this process that expectations are actually defined and is aimed at increasing labor standards, claiming to ensure that everything is done properly. A proper system of quality assurance usually begins with setting expectations (from a range of stakeholders) to which comparisons can be made with respect to actual performance. This can be an internally or an externally conducted evaluation. This evaluation is followed by a planning for actions (for improvement) and ultimately by a review of the changes that the actions have brought. A system or a framework defines how the development of quality is managed, explains how to gather the evidence and how to assess the quality of service, in order to analyze the needs and set objectives on quality development. Quality assurance systems refer to: internal processes - putting in place systems that ensure performance and answer questions such as: are thing being done properly? and of external processes, such as the purpose, values and expectations (results).( Manual on internal systems for ensuring quality in higher education institutions - published by the Accreditation Agency for Higher Education in the Republic of Albania. Taken from the internet: on 13.11.2013 at 23.56h http://www.albranking. com/web/dokumente/manuale/Manual_per\%20NJBSC_30\%20tetr_2012\%20(APAAL).pdf).

An issue, which is taking very little part in the academic debate, is what should be the profile of managers who must have the capacity and skills required to be bearers of these highly complex processes, who will also be able to work closely with the highest levels of management at the university. The profile of such a manager must first be considered from the perspective of the possession of skills and techniques that make management and quality assurance based on the processes and results possible. Said clearly, a manager's involvement should be divided into possession of two core responsibilities: managers or process owners and quality managers. (Manual on internal systems for ensuring quality in higher education institutions - published by the Accreditation Agency for Higher Education in the Republic of Albania. Taken from the internet: on 13.11.2013 at 23.56h http://www.albranking.com/web/dokumente/manuale/Manual_ per\%20NJBSC_30\%20tetor_2012\%20(APAAL).pdf)

Process managers must possess knowledge of all the details of the process and should be responsible for the success of the process, for example the process of assessing the students and the teaching and learning.

The role of quality manager, quality assurance officer, is to measure the effectiveness and efficiency of the process. Furthermore, the role of the quality manager is to conduct a systematic review of the overall operation of the system. Before describing the process, there is a need to identify the strategic objectives of the university, before moving on to the objectives of the single units.

Regardless of the solutions that apply to the segmentation of these tasks and the appointment of managers with managerial competencies for quality assurance operations, the main role lies with the university Rector. (European Platform Higher Education Modernization- http://www.utwente.nl/bms/cheps/publications/publications\%202009/c9hdb 101\%20modern\%20project\%20report.pdf). Therefore, both in the academic field, as well as the legal one, it must be 
stipulated that the roles and main tasks for managing the university processes and operations must be composed by providing the leading role and competence to the Rector of the university. From this, the basis of the work obligations of all segments of management is teamwork and finding opportunities to run the institution in the best way possible. As a leader and manager of the team, the Rector still must possess capacities and powers to realistically analyze the current situation at the university and with professors and students develop long-term goals. Obviously, this must be done through the development of an operational and development plan to achieve such goals. The first step in this journey is the evaluation and assessment of the effectiveness of the actual operations of the university. University institutions carry out analysis and research in order to ascertain their level of performance in comparison with goals, whether at the international, national, regional or at other levels within the university (as articulated in the vision of the university). The vision of the university and that of the Rector must synchronize. The first step in this process is to ask questions like what kind of university we want to become in the long run? What kind and quality of university do we want? How can we provide reliable data about how good our university is? All of these need an assessment and analysis of the current situation in order to identify the desired improvements in the institution.

With the continuous improvement of teaching practices and research, educational leaders create and provide opportunities for students to take advantage of and gain knowledge, develop skills essential for life, and attitudes based on their lives. Successful universities and quality education are achieved as a result of dedicated management and quality work. There can be no quality in an institution without qualitative and effective leadership and management. Effective educational leaders help their institutions to prepare a vision that contains a high level of commitment to teaching and learning, research and advanced research as a prerequisite for quality education in their schools. The Rector has an important role in achieving good quality education. They are managers of some of the most important mitigating and contextual factors (as was presented above) and can effectively influence the teaching process. The work of the Rector is inextricably linked to the quality of education. (http://www.masht -gov.net/advCms/documents/12. Standardet_dhe_Udhezimet_per_Sigurimin_e_Cilesise.pdf)

\section{Standards for Quality Management and Leadership in Universities}

In order to enrich and complement the legal framework in Kosovo, it is essential that MEST prepare a document that will regulate the standards of professional practice for the Rectors of the Universities in Kosovo.( http://www.masht gov.net/advCms/documents/12.Standardet_dhe_Udhezimet_per_Sigurimin_e_Cilesise.pdf) As such, the Rector needs to set the basic standards for this category and serve as a starting point for training and professional development of educational leaders in Kosovo. It is important, however, not to look only on the management aspects. The Rector of the University is responsible for leading the technical issues, but what is more important; he/she is the leader of human beings. Therefore leadership is an important factor for any undergraduate institution. (http://www.utwente.nl/bms/cheps/ publications/publications\%202009/c9hdb101\%20modern\%20project\%20report.pdf)

\section{Legislative Strategy for the Managing Rector's Competence}

In accordance with the legislation on higher education in force, the public Universities in the country have a duty, on the basis of the quality assurance strategy, to prepare its legal/regulatory framework for the upcoming years. The legislative strategy should include the university work plan, taking into account the needs, identity, character and capacities harmonized with the Bologna process and other important documents such as the Magna Charta Universitatum, Lisbon Convention, Sorbonne Declaration, Bologna Declaration, and the Congress of Salamanca. (http://www.utwente.nl/bms/ cheps/publications/publications\%202009/c9hdb101\%20modern\%20project\%20report.pdf)

In particular, universities must have regulations for quality management and assurance, regulations for the work and organization of the Senate and a regulation on the Rector's Council. These regulations should clearly note the competence of the Rector as being a modern and effective manager.

The University, in its quality assurance and management document, must guarantee a regular and sustainable maintenance of an internal structure of quality, which is adequate and above all competent (Towards a European qualifications framework for lifelong learning - Publication of the Commission of the European Communities / Brussels, 08.07.2005 - SEC (2005) 957, this document summarizes the competencies i) cognitive competence involving the use of theories and concepts, as well as informal forms of knowledge gained from experience; ii) functional competence (skills or technical competence), things which a person must be able to perform when in a working environment, social activity or in the process of learning; iii) personal competence involving ways to behave in a specific situation; and iv) ethical 
competence involving the possession of certain personal and professional values.) for the purpose. This requires university governing entities to exercise their powers and to enforce their roles as follows:

$\checkmark$ The Governing Council of the University, as the highest governing body, has clearly defined the authority to adopt the strategic plan on quality assurance and management, thus becoming an important part of the society and university. This body has the ultimate responsibility in this area. ( http://www.utgjiu.ro/revista/ecl pdf/2013-06/37_Avram,\%20Dragusin.pdf)

The Rector should $\bar{b}$ e a competent managerial institution whose authority must lead the quality process and be accountable to the Governing Council. The Rector should legally be responsible for developing quality self-assessment action plan at the University level (Quality Self - Assessment Action Plan) concerning the priorities in different areas. The plan must be submitted for approval to the Governing Council and Senate and supervised by the Center for Excellence and Academic Development.

(http://www.utwente.nl/bms/cheps/publications/publications\%202009/c9hdb101\%20modern\%20project\% 20report.pdf)

$\checkmark$ The Rector shall be responsible for the formation and functioning of the Quality Assurance and Management Commission (QAMC), which would consist of the Rector, Vice Rector, General Secretary, and Executive Advisor, who will draw up, implement and oversee the action plan for quality evaluation and self-assessment. QAMC would also prepare an annual report to the Senate and the Steering Committee for critical review. Technical support is provided by the Quality Assurance Officer. The Commission in the first and second year must meet at least four times during the academic year.

$\checkmark$ The Rector institution should be responsible for strengthening and operationalization of quality assurance teams in each faculty/center, administration and support services bearing responsibility for the self-evaluation process and the implementation of action plans on quality assurance in their fields.

- Faculty teams will be composed of the dean, vice-deans, representatives of the academic staff, student representatives and one external member (stakeholder) selected by the Faculty Council for a one year term, which may be renewed.

- The administration and support services team consists of the supervisors of such services.

$\checkmark$ They all report on a regular basis to the Centre for Quality Assurance and Management on the progress made. They meet at least twice a year. The Center or the Office for Quality Assurance (QAMC) should be the main structure having the authority to coordinate the operation and functioning of quality assurance activities and ensures that the information is distributed and the culture of quality is promoted through a range of mechanisms for communication. The Academic and administrative staff, students and stakeholders are encouraged to participate actively in the development of assessment models as well as the operation and review of the same.(http://www.utgjiu.ro/revista/ec/pdf/2013-06/37_Avram,\%20Dragusin.pdf )

In order to develop a culture of quality, the university must use a variety of internal mechanisms which must be connected to external mechanisms as appropriate, including, but not limited to the following points:

- Development and adoption of curricula to be done in accordance with strict guidelines. The National Accreditation and Assessment Council approves and reviews study programs and students are assessed in accordance with the instructions on evaluation.

- The quality of teaching and learning sustained and developed through an annual observation scheme of the teaching process, annual evaluations by students, staff individual assessment and through professional development opportunities.

- The annual procedure for staff evaluation as an important tool for assessing individual performance, as a basis for renewing the contract and promotion.

- ISO standards on policies and procedures are supervised by teams of trained internal audit on an annual basis and approved by outside agencies on ISO rating.

- The university finances are monitored by the internal audit and also by an external audit office which is internationally accredited.

- The use and development of facilities and resources to be planned and monitored through annual selfassessment and planning process, with priorities related to the strategic plan.

- Satisfaction of the students and staff of the services provided is measured through evaluations by students and through surveys completed by staff.

In order to develop a culture of quality, the Rector institution of the university must consider using a range of external review mechanisms, including, but not limited to the following: 
$>$ European University Association (EUA) (http://www.eua.be/Home.aspx) which provides objective external assessments for a four-year cycle.

$>$ Quality sample, which is taken at least twice a year, which enables checks and evaluations with recommendations for improvement and follow-up.

$>$ Ministry of Education, Science and Technology and other relevant state bodies such as the National Accreditation and Assessment Agency should increase responsibilities for external audits and assessments on licensing new programs and re-approving existing ones.

$>$ External evaluators of study programs should review programs in 3-5 year cycle in order to provide the faculty/academic units with analysis and recommendations to support their development.

External ISO standards would have to apply to the annual revalidation, in order to verify the effectiveness of policies and procedures.

It is, however, important that the document in question and the processes and structures responsible for quality assurance and management be reviewed on an annual basis by the Commission on Quality Assurance and Management and quality teams from the faculties/departments. The Universities still need to establish clear organizational structures which should include: A central office staff specialized on quality assurance, a quality manager that assigns and manages a network of quality assurance staff in all units at the university; otherwise, quality assurance functions may also be included in different organizational units of the institution. (http://www.cbs.dk/en/about-cbs/organisation/seniormanagement/news/the-role-of-universities-in-modern-societies)

\section{Conclusions}

Universities have a legal, ethical and academic obligation to take all necessary action to ensure the quality and sustainability of study programs in the context of the European Area of Higher Education. They should pursue policies that help to improve them. Quality standards, which the universities in the Republic of Kosovo should provide, represent the entirety of requirements and criteria that must be met in its functioning, and at the same time serve as a set of recommendations that help higher education institutions to reach a certain level of development. Criteria are standard elements, accessible and verifiable, clearly defined upon which the institutions must fulfill their mission and which are used to make an assessment, a classification, etc.

The universities should follow and implement their own policies to meet the mission defined at the moment of inception and support the legal framework on higher education in the Republic of Kosovo. The university institutions should use their autonomy to adapt it and implement it according to the laws and regulations in force, in order to fulfill their mission. The governing bodies should be involved in drafting and implementing the strategy for institutional development. For the implementation of strategic projects, institutions engage academic staff, educational and scientific support staff, and administrative staff with the required competence. In order to create partnerships, the institution cooperates with all stakeholders, especially with other institutions of higher education. The Rector maintains regular contact with units and their subsidiaries, as well as with different categories from the business world, be they local or foreign. He takes part in leading scientific networks and assumes membership in national and international scientific structures.

Higher education institutions have the right to divide into organizational constituent units: main, base and auxiliary units, to exercise the autonomy within their power. The constituent units of the Institution of Higher Education should be involved in the development and implementation of the institutional project. The managing authority of the institution is responsible for the implementation of the decisions taken by the governing bodies and the management of the Higher Education Institution. They pursue a policy that is favorable to the efficient management of human resources, while respecting an open recruitment and employment policy within human resources.

The universities must pursue an active policy to encourage the development at regional, national and international levels. They should be accompanied by supporting policies on mobility and reception of students, PhDs, scientific research personnel (domestic and foreign), through an institution partnership. The provision of a suitable environment and infrastructure for academic and scientific activity is also deemed important. The institution designs the budget in accordance with the laws and regulations in force as well as in line with the development and publication policies in the official website, for all statistical data on the number of students under the programs, the academic offerings, operation of the institution, and statutes and regulations in effect.

All these tasks require a Rector institution which, other than coming from the academic world, possesses specific management skills and abilities required for the development and management of a modern university. 


\section{References}

Marioara A \& Cristina - Petrina D., "The Management and content of managerial functions in Romania Universities" http://www.utgjiu. ro/revista/ec/pdf/2013-06/37_Avram,\%20Dragusin.pdf

European Platform on Higher Education Modernisation - http://www.utwente.nl/bms/cheps/publications/Publications\%202009/C9HdB 101\%20MODERN\%20PROJECT\%20REPORT.pdf

"The University Rector 'Introduction to the Role of University Rector in Scotland - https://www.st-andrews.ac.uk/media/court-office/ documents/court_rector_role.pdf

Manual on the Development of the Excellence in Higher Education Framework, Bucharest, Cork, Graz, Pristina, Salzburg, 2011, taken from the web; http://www.wus-austria.org/files/docs/Quality\%20Assurance\%20Manual\%20_FINAL_ALBANIAN.pdf

Standards and Guidelines for Quality Assurance in the European Higher Education - European Association for Quality Assurance in Higher Education; for more see http: //www.masht -gov.net/advCms/documents/ 12.Standardet_dhe_Udhezimet_per_Sigurimin_ e_Cilesise.pdf

Shutterstock ,. The Role of Universities in Modern Societies ,. http://www.cbs.dk/en/about-cbs/organisation/senior-management/news/ the-role-of-universities-in-modern-societies

\section{Web}

http://www.eua.be/Home.aspx

http: //www.masht -gov.net 